\title{
LEIOMIOSSARCOMA DE VEIA CAVA INFERIOR
}

\section{LEIOMYOSARCOMA OF THE INFERIOR VENA CAVA}

\author{
Eduardo Crema, TCBC-MG'; Marília Gabriela Zanier Gomes²; \\ Isabela de Oliveira Monteiro ${ }^{2}$; Alex Augusto Silva ${ }^{3}$; Adilha Misson Rua Micheletti ${ }^{4}$
}

\section{INTRODUÇÃO}

O leiomiossarcoma de veia cava inferior é um raro tumor maligno, descrito inicialmente por Perl em 1871. Mingoli et $a l^{1}$ descreveram a análise de uma série mundial de 218 pacientes com tal lesão, incluindo os conhecidos no Registro Internacional de Leiomiossarcoma de Veia Cava Inferior de 1996. De acordo com essa análise, o segmento médio da veia foi o mais acometido ( $44 \%$ das vezes), seguido pelo segmento inferior (37\%) e pelo superior (19\%). Além disso, $61,5 \%$ dos pacientes foram submetidos à ressecção cirúrgica radical e $26,6 \%$ se mostraram inoperáveis. O presente caso relata um leiomiossarcoma de VCI cujo tratamento realizado foi a ressecção completa da lesão em bloco com o segmento comprometido da veia.

\section{RELATO DO CASO}

Paciente de 50 anos, sexo feminino, deu entrada no serviço de emergência referindo dor em mesogastro e em flanco direito há sete meses, com irradiação para região lombar direita. Relatava, também, aparecimento de massa abdominal dois meses após início da dor, além de hematúria macroscópica e perda ponderal de $10 \mathrm{Kg}$.

No exame físico, o abdome apresentava uma massa palpável não pulsátil, dolorosa, endurecida e com pouca mobilidade em mesogastro e flanco direito. A paciente foi, então, internada para elucidação diagnóstica, e iniciou a realização de exames complementares.

Na ultra-sonografia (US) abdominal foi visualizada massa heterogênea, hipoecóica, de contornos lobulados, localizada na região peri-aórtica à direita, de dimensões $10,6 \times 6,3 \mathrm{~cm}$.

Na tomografia computadorizada (TC) de abdome, foi detectada lesão expansiva de retroperitônio de contornos definidos e densidade heterogênea, comprimindo a VCI e deslocando a aorta para a esquerda; compatível com sarcoma retroperitoneal.

A paciente foi, então, submetida à laparotomia com incisão transversa supra-umbilical, a aproximadamente $7 \mathrm{~cm}$ dos rebordos costais. Foi identificada uma massa de $15 \times 10 \mathrm{~cm}$ aderida ao retroperitônio, englobando a VCI nos segmentos médio e inferior (Figura 1). Realizou-se dissecção e extirpação da massa e da VCI acima e abaixo da lesão. Como a mesma invadia a veia renal direita, optou-se pela ligadura da $\mathrm{VCI}$ ao nível das veias ilíacas e imediatamente abaixo da veia renal esquerda. Foi realizada, então, ressecção da massa em bloco com o segmento da VCI, rim direito e gordura perirenal direita. A paciente evoluiu sem complicações.

No exame anátomo-patológico da peça cirúrgica, a microscopia revelou neoplasia hipercelular, crescendo a partir da parede de uma grande veia, constituída de células fusiformes com núcleos hipercromáticos e, às vezes, pleomórficos, formando grandes fascículos. Havia extensa necrose e freqüentes mitoses, por vezes atípicas (Figura 2). $\mathrm{O}$ estudo imuno-histoquímico evidenciou diferenciação muscular: a neoplasia foi positiva para actina de músculo liso (1A4), para actina músculo específica (HHF35) e para desmina; negativa para proteína S-100 e para citoceratina. Foi feito, então, o diagnóstico de leiomiossarcoma Grau 2 em quatro de malignidade histológica, crescendo a partir do segmento médio da VCI.

\section{DISCUSSÃO}

Leiomiossarcoma de VCI é um raro tumor retroperitoneal. A média de idade dos pacientes do Registro
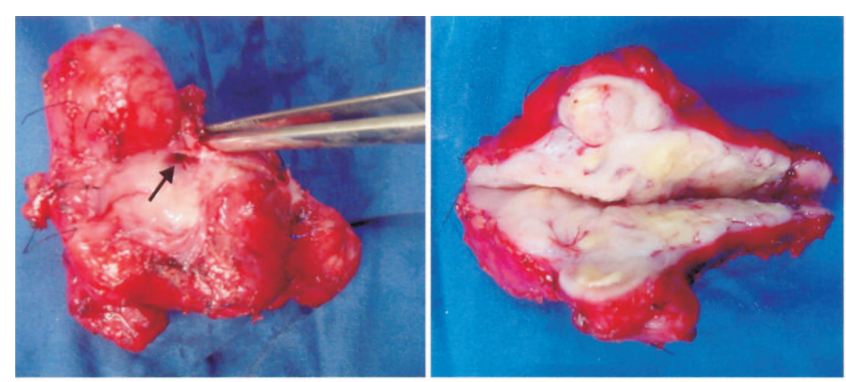

Figura 1 - Nota-se lesão acometendo e estenosando a veia cava inferior (seta). A superfície de corte mostra o aspecto brancacento e infiltrativo característico da lesão.

1. Professor titular da Disciplina de Cirurgia do Aparelho Digestório da UFTM (Universidade Federal do Triângulo Mineiro).

2. Acadêmica do sexto ano de medicina da UFTM.

3. Professor responsável pela disciplina de Cirurgia do Aparelho Digestório da UFTM.

4. Mestrado em Anatomia Patológica e Professora assistente da Disciplina de Patologia Especial.

Recebido em 08/03/2006

Aceito para publicação em 15/04/2006

Conflito de interesse: nenhum

Fonte de financiamento: nenhuma

Trabalho realizado na Universidade Federal do Triângulo Mineiro (UFTM). 
Internacional de leiomiossarcoma de VCI é de 54 anos (15 a 85 anos) ${ }^{1}$, com predomínio do sexo feminino sobre o masculino $(5: 1)^{2}$. Isso condiz com nosso relato, em que a paciente apresentava 50 anos e era do sexo feminino.

Esse tumor possui um crescimento lento, o que frequientemente retarda o diagnóstico e mantém os pacientes assintomáticos por um longo tempo. A descoberta é feita incidentalmente em 10,5\% dos pacientes e através de autópsia em $33 \%^{3}$. As manifestações clínicas dependem, principalmente, do segmento da VCI envolvido, sendo que as mais comuns são: síndrome de Budd-Chiari (segmento superior); dor abdominal (porção média) e massa palpável (porção inferior). O tumor pode, também, envolver mais de um segmento, o que gera uma combinação de sinais e sintomas ${ }^{4}$. A nossa paciente apresentava tal combinação de sintomas (dor e massa palpável) por ter as porções média e inferior da VCI acometidas.

Os exames pré-operatórios de maior acurácia para essa lesão são: tomografia computadorizada e ressonância magnética. Entretanto, a comprovação diagnóstica só é possível após estudo histopatológico da peça.

A ressecção cirúrgica completa é a única modalidade terapêutica comprovada capaz de prolongar a sobrevida dos pacientes e deve ser indicada o mais precocemente possível, com uma sobrevida em 5 anos de 49,4\% ${ }^{1}$. O papel da radio e/ ou quimioterapia (terapias adjuvantes) ainda não está bem definido.

O prognóstico é ruim. Contribuem para isso: envolvimento do segmento superior da VCI, síndrome de BuddChiari, crescimento intraluminal do tumor e oclusão da VCI. A

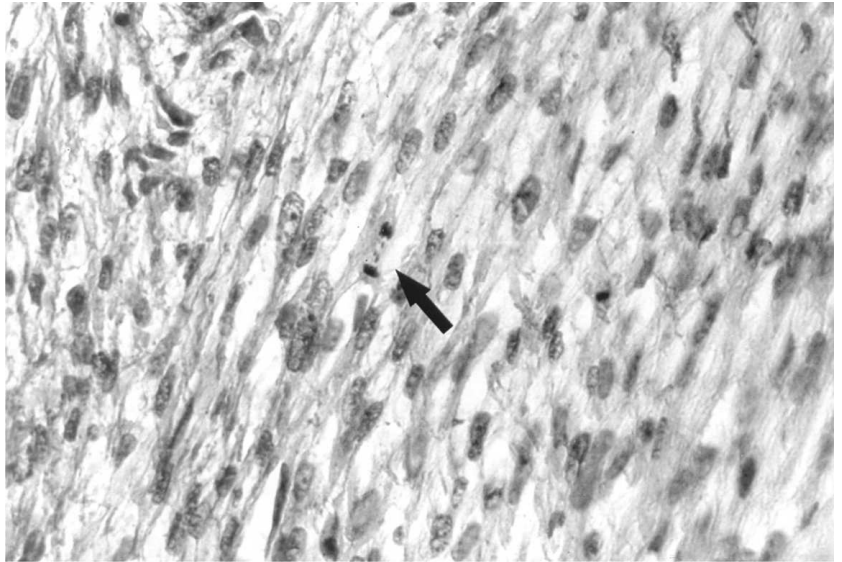

Figura 2 - Fotomicrografia do leiomiossarcoma mostrando as células fusiformes atípicas, organizadas em fascículos longos. Notar mitose no centro do campo (seta). (HE-400x).

recidiva da doença foi mostrada em mais de $50 \%$ dos casos, com metástases freqüentes ${ }^{5}$.

A reconstrução da veia nem sempre é necessária, tendo-se em vista que a oclusão gradual da mesma permite o desenvolvimento de circulação colateral. No caso em questão, a ligadura da veia cava não prejudicou o retorno venoso da paciente.

\section{AGRADECIMENTO}

Agradecemos à professora Dra. Sheila Jorge Adad, pela contribuição na descrição anátomo-patológica da peça cirúrgica.

\begin{abstract}
Leiomyosarcoma of the inferior vena cava is an extremely rare tumor, and it is reported to have a poor prognosis. The clinical findings are nonspecific and may precede the diagnosis by several years. Symptoms depend on the location and extension of the tumor. A complete surgical resection is the only proven therapeutic modality that prolongs the survival in patients with this lesion. We report a case of a 50 year-old patient with inferior vena cava leiomyosarcoma, who was submitted to a surgical treatment (Rev. Col. Bras. Cir. 2008; 35(6): 447-448).
\end{abstract}

Key words: Leiomyosarcoma; Vena cava, inferior; Retroperitoneal neoplasms.

\title{
REFERÊNCIAS
}

1. Mingoli A, Cavallaro A, Sapienza P, et al. International registry of inferior vena cava leiomyosarcoma. Analysis of a world series on 218 patients. Anticancer Research. 1996; 16(5B):3201-5.

2. Ahluwalia A, Saggar K, Sandhu P, et al. Primary Leiomyosarcoma of inferior vena cava: An unusual Entity.Ind J Radiol Imag. 2002; 12(4):515-6

3. Hardwigsen J, Balandraud P, Ananian P, et al. Leiomyosarcoma of the retrohepatic portion of the inferior vena cava: Clinical presentation and surgical management in five patients. J Am Coll Surg. 2005; 200(1):57-63.

4. Nikaido T, Endo Y, Nimura S, et al. Dumbbell-shaped leiomyosarcoma of the inferior vena cava with foci of rhabdoid changes and osteoclast-type giant cells. Pathol Int. 2004; 54(4):256-60.
5. Kwon TW, Sung KB, Cho YP, et al. Pararenal Leiomyosarcoma of the inferior vena cava.J Korean Med Sci. 2003;18(3):355-9.

Como citar este artigo:

Crema E, Gomes MGZ, Monteiro IO, Silva AA, Micheletti AMR. Leiomiossarcoma de veia cava inferior. Rev Col Bras Cir. [periódico na Internet] 2008; 35(6). Disponível em URL: http://www.scielo.br/rcbc

Endereço para correspondência

Eduardo Crema

Rua Marcos Lombardi, número 305

Bairro Santa Maria

38050-170 - Uberaba - MG

E-mail: cremauftm@mednet.com.br 